\title{
Latitudinal and cross-shelf patterns of size, growth and mortality of a tropical damselfish Acanthochromis polyacanthus on the Great Barrier Reef
}

\author{
Michael Kingsford ${ }^{*}$, David Welch ${ }^{2}$, and Mark O'Callaghan ${ }^{1}$ \\ 1 Marine Biology and Aquaculture, College of Science and Engineering and ARC Centre of Excellence for \\ Coral Reef Studies, James Cook University Qld 4811, Australia; michael.kingsford@jcu.edu.au \\ $2 \mathrm{C}_{2} \mathrm{O}$ Pacific, Port Vila Vanuatu \\ * Correspondence michael.kingsford@jcu.edu.au
}

\begin{abstract}
:
Patterns of age and growth of a sedentary damsel fish Acanthochromis polyacanthus were tested over a latitudinal range of approximately 10 degrees $(1,200 \mathrm{~km})$ on the Great Barrier Reef, Australia. Within latitudes these patterns were also compared on reefs across a continental shelf that ranged in width from 52 to $128 \mathrm{~km}$. Although variation in length-max, growth, age-max and the von-Bertalanffy metrics of $\mathrm{L}_{\infty}$, and $\mathrm{K}$ were found within and among latitudes, greatest variation in some demographic characteristics were found across the shelf regardless of latitude. Fish were always smaller at inner shelf reefs and grew more slowly when compared to mid and outer shelf reefs. The oldest fish collected was 11 years old and, there were no consistent variation in age-max among distances from shore. On outer reefs, there was a linear relationship with age-max and latitude. This 'tropical gradient' of age only explained $34 \%$ of the variation, further this was not found when the oldest $10 \%$ of fish were considered. Fish only reached an age-max of 6 years on the southern-most reefs. There was a trend for a smaller $\mathrm{L}^{\infty}$ with latitude but, it was not significant and $\mathrm{L}^{\infty}$ did not vary predictably with water temperature. The sampling of MPAs did not confound the resultant patterns. Instantaneous mortality rates were $0.245-0.685$, highest at inner reefs and showed no consistent MPA-related patterns. Our study suggested that the mid and outer shelf waters of the GBR appeared best suited for growth of A. polyacanthus. In conclusion, position on continental shelves and related local environmental conditions needs to be considered in spatial models of growth.
\end{abstract}

Keywords: reef fish, age, growth, mortality, Great Barrier Reef, Pomacentridae, cross-shelf, MPA, latitudinal gradients.

\section{Introduction}

Patterns of age, growth and mortality are critical to understanding the population dynamics of fishes. These patterns are influenced by internal factors such as genetics and, related physiological tolerances (Conover 1997) [1] as well as environmental factors [2]. Further, growth and mortality can be influenced by fishing effort (e.g., growth compensation [3]) and related variation in fishing effort in an out of Marine Protected Areas (MPAs [4]).

Environmental factors have often been correlated with demographic characteristics. There are a number of models that relate to latitude and sea water temperature. Tropical Gradient Models (TGM) state that one or a combination of age-max, length-max, growth and growing season decrease from low latitude to high latitude $[1,2,5]$. This pattern closely aligns with the Temperature Size Rule (TSR) where reduced growth rate correlates with a drop in temperature. In some cases, however, this is the pattern for growth whilst length to infinity can increase with 
latitude [6]. Counter Gradient models (CGM) state that age-max, length-max or growth will increases from low latitude to high latitude (e.g., [5, 7]). In the case of some surgeon fishes, age-max increases with a decrease in temperature but, due to variation in oceanography does not increase as predictably with latitude[8]. Bergmann's Rule and 'James Rule' refer to an increase in body size with latitude $[9,10]$. At some spatial scales regional differences in demographics are not been found to vary predictably over many degrees of latitude (e.g., 12 ${ }^{\circ}$, Cromileptes altivelis [11] ). For any correlative study it is often challenging to provide a strong case any of these patterns without sampling a wide latitudinal range and having multiple sampling sites.

The Great Barrier Reef (GBR) is about $2000 \mathrm{~km}$ long; accordingly, it covers a broad latitudinal range of approximately $14^{\circ}$. Furthermore, the width of the continental shelf ranges from $60 \mathrm{~km}$ to $300 \mathrm{~km}$ wide. A concern is that latitudinal variation could be confounded by position across the shelf. It is well documented that there is more variation in the abundance of and species richness cross-shelf than over long distances latitudinally [12-15]. Moreover, it is well known that with position on the continental shelf there will be differences in environmental drivers. For example, coastal process such as riverine runoff and related sediment loads [16, 17]) and, on the outer shelf proximity to upwelling [18]; by deduction these factors could also have a great influence on the supply of planktonic food. These processes could have a great influence of patterns of size/age and growth [13] that are independent to latitude. Gust et al. [19] demonstrated such differences for the size max, growth and mortality for some species of scarids and one acanthurid at replicate reefs positioned mid shelf or outer shelf on the GBR.

The level of protection of reefs from fishing can also have an impact on demographic metrics and mortality that could confound the interpretation of broad spatial patterns. Protection generally results in greater abundance as well as larger and older fish [20-22]. Furthermore, a high abundance of predatory fishes could affect patterns abundance of prey and the size/age and growth characteristics of reef based populations (e.g., [4]). Kingsford \& Hughes [23] found great differences in size maxima and von-Bertalanffy characteristics of fish across the shelf, where fish from inner reefs were much smaller. However this project did not test for variation in demographic characteristics with latitude and did not consider the confounding effects of levels of marine protection.

The objective of this study was to compare the demographic characteristics of A. polyacanthus cross-shelf and over a latitudinal range of $\sim 9$ degrees (about $1200 \mathrm{~km}$ ). Our approach was to sample with high spatial resolution at replicate reefs and multiple latitudes from the northern to southern GBR. Where geomorphology allowed, we sampled at multiple distance strata from shore (inner, mid and outer shelf). The specific aims of this study were to: (1) describe patterns size, age and growth of reef-based populations of $A$. polyacanthus with latitude and within and among sampling strata at different distances from shore; (2) calculate the instantaneous mortality rates $(Z)$ of populations of $A$. polyacanthus with latitude and within and among distance strata; (3) we also tested a hypothesis that the level of marine protection could confound broad scale spatial patterns. A. polyacanthus was an ideal species for the study of patterns of size, age and growth as it is found over a broad latitudinal range and on reefs at inner, mid and outer distances across the continental shelf $[12,24]$. Furthermore, the distribution and abundance of the species allowed for high spatial resolution of the aforementioned patterns. 
Figure 1. Location of sampling sites for Acanthochromis polyacanthus on the Great Barrier Reef with inserts indicating latitudinal positions as follows. Lizard (a), Townsville (b), Whitsunday (c), Swains (d) and Capricorn/Bunker (e). Outlines of the colour morphs of Acanthochromis polyacanthus by latitude are provided, larger images in colour are provided in Figure S1.

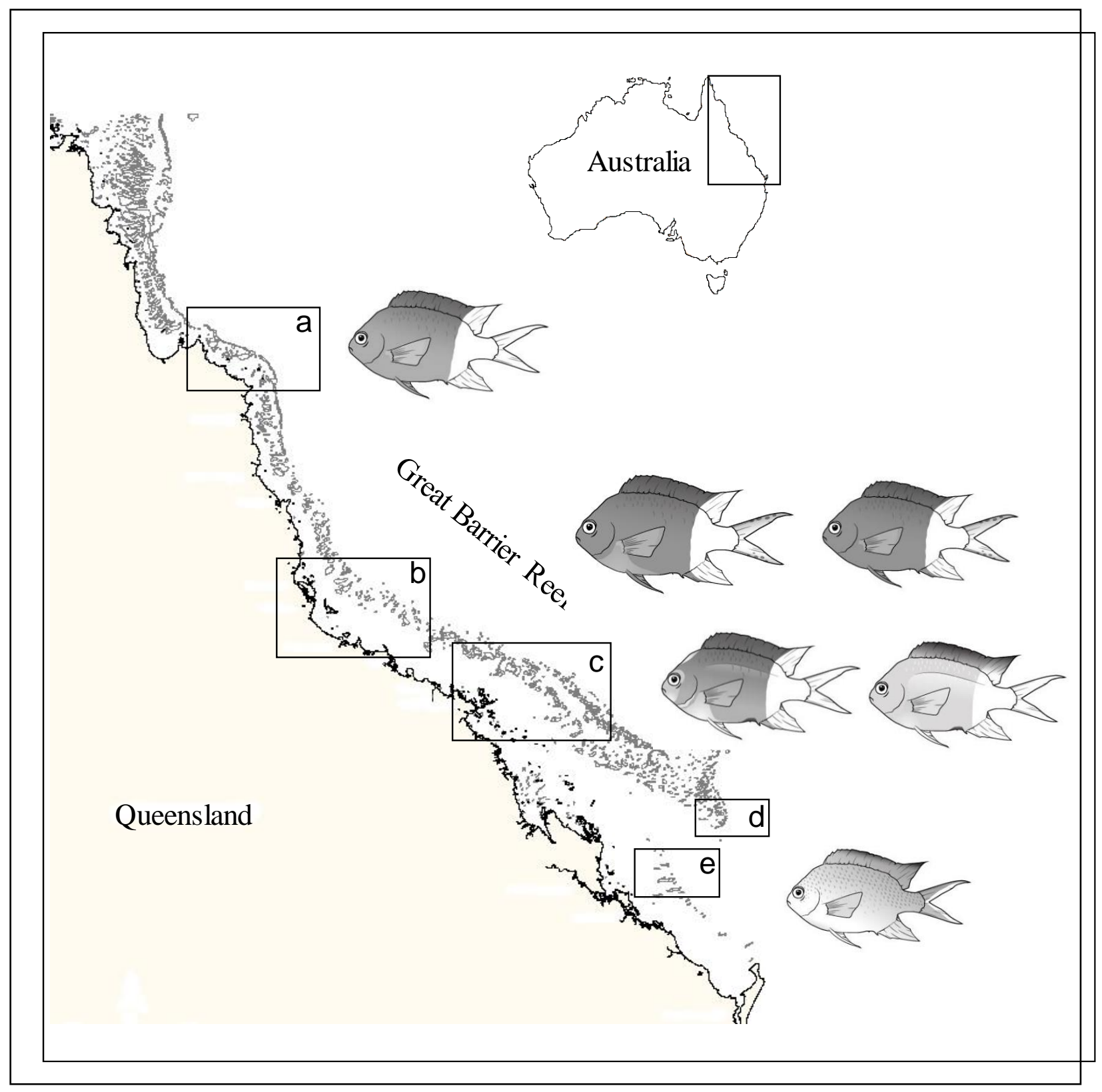




\section{Materials and Methods}

\subsection{Study Sites and Sampling Design}

Spatial variation in demographics and structures of cross-shelf populations of A. polyacanthus was determined using a partially hierarchical sampling design. Individuals of a wide range of sizes were collected from two or three sites from two or three replicate reefs within each of three distance strata (inner, mid- and outer-shelf) spanning the width of the continental shelf at three latitudes, Lizard Island, Townsville and the Whitsundays (Townsville data are from [23]. Additional outer shelf sites were located in the Swains, and the Capricorn section in the GBR (Figure 1, Table 1). At each site, a minimum of 40 fish were collected using hand spears from 2001-2006 (Table 1). The environmental gradient of temperature with latitude with was as follows. Seawater temperatures were up to $4{ }^{\circ} \mathrm{C}$ lower in the Capricorn Bunker Group in winter and about 2 degrees cooler in summer when compared with Lizard. Further, temperatures were about $1^{\circ} \mathrm{C}$ lower on outer reefs of the Townsville latitude in winter and similar in summer when compared with Lizard (Fig. S2). Hobo data loggers were used to collect these data at 10 and 30m deep at outer reefs of each latitude over a period of two years.

Although Acanthochromis polyacanthus is considered as single species on the GBR, there is variation in color morphs by latitude and distance from shore (see [25]. In some sections of the GBR A. polyacanthus are of the same color morph and these morphs can be genetically isolated (Central GBR, [26], while more than one colour morph were was found at some latitudes (Whitsundays Section). Accordingly, we were careful to note the colour morph of A. polyacanthus by distance from shore and latitude in case incipient speciation could explain some of the differences in demographic characteristics that we detected Fig. 1.

\subsection{Processing of samples}

All fish were measured to the nearest $\mathrm{mm}$ (Standard Length, SL). Sagittal otoliths were extracted, cleaned in MQ water to remove the sagittal membrane and allowed to dry overnight. One otolith from each fish was then sectioned using a Gemmasta GF4 Faceting Machine using a 1200 grit diamond disc and Crystal bond thermoplastic glue.

\subsection{Analysis of growth increments}

The opaque zones visible in the internal structure of the otolith were counted along a radius from the primordium to the outer edge of the largest sagittal lobe of the otolith using a compound microscope (Leica DMLB) and white incident light source. Alternating translucent and opaque increments were interpreted as annuli. This has previously been validated by Kingsford and Hughes [23]. Sections were coded and examined in random order and the opaque increments counted on two occasions by the same observer separated by four days. Counts of annuli were compared between these two occasions in order to assess the confidence that could be placed in the interpretation of otolith structure. If increment counts differed then the otoliths were re-examined. If, following a third reading, agreement was not reached then the otolith was not included in the analysis; $6.6 \%$ of otoliths were rejected on this basis ( $n=186$ fish). Fish that could not aged were still included in the results relating to standard length only.

Spatial patterns of oldest age (10\%) and largest fish SL (10\%) over a latitudinal range of 10 degrees were tested with a fully hierarchical ANOVA as follows: Latitude $(a=5)$, reefs (latitude), $b=2$; $\mathrm{n}=7$ fish. So that distance across the shelf and latitude were not confounded this analysis was only done on 13 outer shelf reefs. Sample size was determined by the smallest $\mathrm{n}$ at a reefs, this allowed us to do a more robust balanced ANOVA (Underwood 1997)[27]. Data were tested for normality, in the case of SL $(10 \%)$ the data were still heterogeneous after transformation; because ANOVA is 
robust to heterogeneity we continued with the analysis. Linear relationships between latitude and demographic variables were done with least squares regressions.

Table 1. Location and numbers of Acanthochromis polyacanthus collected from September 2001 to January 2006.

\begin{tabular}{|c|c|c|c|c|c|}
\hline Latitude & Shelf & Total $n$ & Reef & $\mathrm{N}$ & Dates Collected \\
\hline \multirow[t]{7}{*}{ Lizard } & \multirow[t]{2}{*}{ Inner } & \multirow[t]{2}{*}{279} & Martin & 162 & Nov 2004 \\
\hline & & & Linnet & 116 & Nov 2004 \\
\hline & \multirow[t]{3}{*}{ Mid } & \multirow[t]{3}{*}{237} & Eagle Ilet & 99 & Dec 2001 \\
\hline & & & North Direction Is. & 57 & Dec 2001 \\
\hline & & & MacGillivray & 111 & Dec 2001 \\
\hline & \multirow[t]{2}{*}{ Outer } & \multirow[t]{2}{*}{293} & Yonge & 155 & Dec 2001 \\
\hline & & & Day & 138 & Dec 2001 \\
\hline \multirow[t]{9}{*}{ Townsville } & \multirow[t]{3}{*}{ Inner } & \multirow[t]{3}{*}{156} & Havannah Island & 70 & Sep 2001 \\
\hline & & & Orpheus Island & 41 & Sep 2001 \\
\hline & & & Pandora & 45 & Sep 2001 \\
\hline & \multirow[t]{3}{*}{ Mid } & \multirow[t]{3}{*}{286} & Britomart & 88 & Oct 2001 \\
\hline & & & Bramble & 105 & Oct 2001 \\
\hline & & & Slashers & 93 & Oct 2001 \\
\hline & \multirow[t]{3}{*}{ Outer } & \multirow[t]{3}{*}{298} & Barnett Patches & 116 & Oct 2001 \\
\hline & & & Pith & 100 & Oct 2001 \\
\hline & & & Myrmidon & 82 & Oct 2001 \\
\hline \multirow[t]{6}{*}{ Whitsunday } & \multirow[t]{2}{*}{ Inner } & \multirow[t]{2}{*}{232} & Hook Island & 105 & Sep 2003 \\
\hline & & & South Mole & 127 & Sep 2003 \\
\hline & \multirow[t]{2}{*}{ Mid } & \multirow[t]{2}{*}{173} & Line & 84 & Sep 2003 \\
\hline & & & Net & 89 & Sep 2003 \\
\hline & \multirow[t]{2}{*}{ Outer } & \multirow[t]{2}{*}{169} & Elizabeth & 79 & Sep 2003 \\
\hline & & & Ellen & 90 & Sep 2003 \\
\hline \multirow[t]{3}{*}{ Swains } & \multirow[t]{3}{*}{ Outer } & \multirow[t]{3}{*}{215} & Hixson Cay & 82 & Jan 2006 \\
\hline & & & Sweetlips & 70 & Jan 2006 \\
\hline & & & Sandshoe & 66 & Jan 2006 \\
\hline \multirow[t]{3}{*}{ Cap/Bunker } & \multirow[t]{3}{*}{ Outer } & \multirow[t]{3}{*}{245} & One Tree Island & 97 & Jan/Feb 2002 \\
\hline & & & Lamont & 73 & Jan/Feb 2002, Feb 2006 \\
\hline & & & Heron Island & 86 & Jan/Feb 2002 \\
\hline
\end{tabular}

\subsection{Growth}

It was hypothesized that patterns of growth would vary with distance from the coast and between different latitudes. Growth was described using the von Bertalanffy growth function (VBGF) which provided the best fit to size-at-age data when compared with estimates of the Schnute growth function [28]. 
The von Bertalanffy expression for length at age $t(L t)$, as a function of time is:

$$
L_{t}=L_{\infty}\left[1-\mathrm{e}^{-K\left(t-t_{0}\right)}\right]
$$

where $L_{t}=$ length at age $t$ (years); $L_{\infty}=$ the mean asymptotic standard length; $K=$ the rate at which the growth curve approaches $L_{\infty}$, and $t_{0}=$ the age at which the fish have a theoretical length of zero. Kingsford and Hughes [23] demonstrated that variation in growth for A. polyacanthus off Townsville on the GBR was greater among distance strata than within distance strata. Accordingly, we tested the robustness of this pattern among the regions where all distance strata could be sampled.

An orthogonal design was used to test for spatial patterns in size, age, growth and mortality across the shelf (Distance strata: inner, mid and outer-) and among three latitudes as follows: Lizard Island, Townsville and Whitsunday. We did find significant differences in demographic characteristics across the shelf. So that distance and latitude were not confounded a further analysis was done on outer reef only. Further, to increase latitudinal coverage in addition to Lizard Island, Townsville, Whitsunday, additional samples were taken from the Swains and the Capricorn-Bunkers (Table 1). Spatial patterns for the top 10\% of fish by length and age were tested using balanced ANOVA designs as follows: (1) A partially hierarchical design for comparisons among distances from shore (Factor Distance, Fixed), at three latitudes (Factor Latitude, Fixed) with two sites at each distance (nested in $L^{*} D$ ). (2) Comparisons were made with a fully hierarchical design among five random latitudes (Factor Latitude, random) and there were two reefs nested in latitude. (3) To determine if the GBR marine zoning plan consisting of fully fished and unfished reefs could confound our interpretation of spatial patterns of age and size we selected fished and unfished reefs that were close. Pairs of reefs with the two different types of zones (Factor Zone, fixed) were available at Inner and Outer distances from shore (Factor Distance, fixed), there were two locations at each distance stratum that had this pairing and therefore 'location' was nested in distance [Factor Loc(distance), random]. All analyses were done according to Underwood [27]. Data were analyzed for heterogeneity with Cochran's tests.

The spatial hierarchy of growth patterns was visualised by generating cross sections of the approximate $95 \%$ confidence regions around $L \infty$ and $K$, by constraining to to a common value by fitting a VBGF to all size-at-age data for the curves being compared. We formally tested the visual separation of $95 \%$ confidence intervals among regions and distance strata using likelihood ratio tests (Kimura, 1980). This test is considered the most reliable procedure for comparing non-linear curves (Cerrato, 1990). These tests were done on paired comparisons among reefs at different latitudes; these results are compared in Table SP1. Comparisons of size at age were also made for two and three year olds as this corresponded to the fastest period of growth before fish reached $\mathrm{L}^{\infty}$.

\subsection{Mortality}

The instantaneous rate of mortality $(Z)$ was calculated using log-linear regression analyses of age-frequency data sets for $A$. polyacanthus populations from each reef sampled [29]. This method assumes that recruitment is consistent over time at each reef. The natural logarithm of the number of fish sampled from each age class was compared with their corresponding age. Year classes to the left of the age-frequency mode were excluded from the analysis because our sampling technique was biased against small A. polyacanthus. Fish greater than $60 \mathrm{~mm}$ were collected representatively, ie as they were encountered. The slope of the regression line between year classes estimated the instantaneous mortality rate $(Z)$ :

$$
Z=F+M
$$

where $F$ is fishing mortality and $M$ is natural mortality [19]. Since there is not a fishery for A. polyacanthus on the GBR, $F$ equals zero and therefore $Z$ estimates natural mortality only. Annual survival rate estimates were then calculated according to the equation $S=\mathrm{e}^{-Z}[30]$ and are presented 
as percentages. Data from each site were pooled for each reef because in many cases sample sizes were too small to provide reliable estimates of mortality at the site level. Similarities in mortality rates among replicate reefs within distance strata allowed pooling of data the strata level so that comparisons of mortality between shelf positions could be made.

\section{Results}

\subsection{Colour morphs}

The colour morph of $A$. polyacanthus varied by latitude and on some occasions with distance within a latitude. Fish collected either of the brown and white colour morph for the Cairns; brown and white colour at the Townsville latitude and sometimes with a gold-yellow chin at inner sites; brown and white colour, with a gold-yellow chin and similarly coloured head, with a purple/blue vent for inner Whitsundays and at mid and outer reefs a pale greenish anterior and white posterior with purple/blue vent. In contrast, at the Swains and Capricorn/Bunker group fish were a slaty grey with darker highlights on the distal end of scales and on the edges of the fins (Colour images Figure 1, S1).

Figure 2. Length-frequency distributions for A. polyacanthus collected from the 13 positions on the GBR (reefs pooled within distances) LOW RESOLUTION IMAGE.

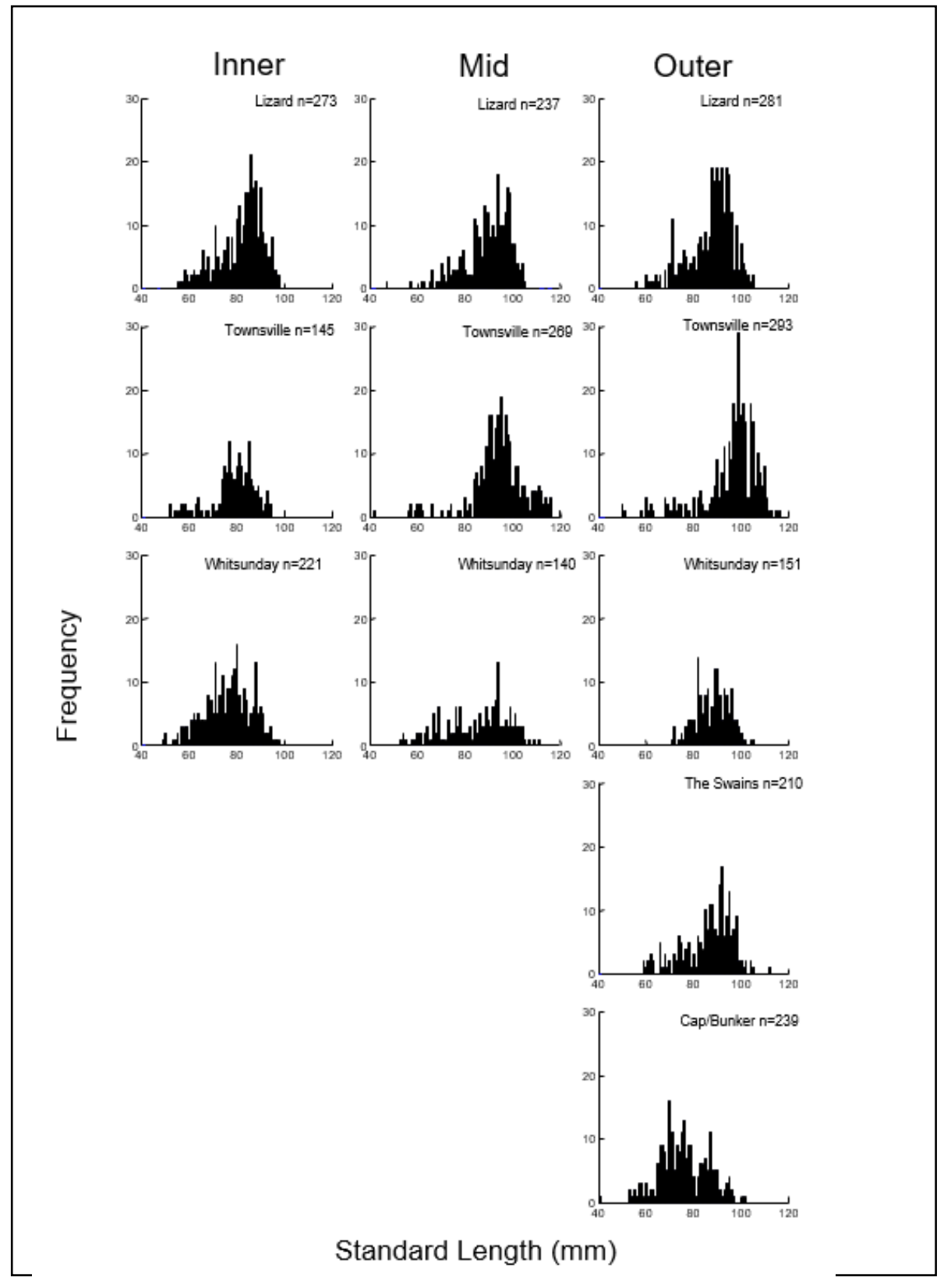




\subsection{Size, age and growth}

There were consistent patterns of length frequency and maximum length (LMAX) across the continental shelf at three latitudes (Figure 2, Table 2). Fish were generally shorter at all inner reefs and it was rare for fish to be over $95 \mathrm{~mm} \mathrm{SL}$. In contrast, A. polyacanthus were over a $100 \mathrm{~mm} \mathrm{SL}$ at mid and outer reefs where this was most obvious at the Townsville latitude (Max lengths of fish were 6-20 $\mathrm{mm}$ shorter at inner reefs when compared to maxima recorded at mid and outer reefs). Max lengths of the largest $10 \%$ of fish showed a similar trend to SLmax. Although there was a clear pattern for the largest fish on reefs to be small at inner strata, a significant interaction between Distance and latitude indicated that the magnitude of differences varied between inner reefs and those at mid and outer strata (Table 3). The differences across the shelf were least obvious on reefs of the Lizard island latitude and were greatest at reefs of the Townsville latitude. Local variation in growth between sites within distance strata was also found [Site $\left(L^{*} \mathrm{D}\right)$, Table 3), but this did not obscure the broad differences found across the shelf.

Among latitudes of outer reefs fish the only clear pattern was that the size max of A. polyacanthus was at outer reefs off Townsville. Although 29\% of the variation in SL10\% was explained by latitude this factor was not significant (Table 4). Fifty-eight percent of the variation was explained by differences, on a scales of kilometres to tens of kilometres, between reefs within latitudes and only $13 \%$ at the level of replication. When the top $10 \%$ of fish was considered there was no relationship between SL and latitude. Further, there were no significant linear relationships between SL max or SL10\% and latitude for fish from all latitude and nested reefs $(\mathrm{n}=13)$; in both cases ANOVA indicated that the slopes for these linear comparisons were not significantly different from zero. There was little evidence that temperature was a primary driver in patterns of SL with latitude as SLmax 10\% was much larger at Townsville when compared to Lizard, but seawater temperatures were similar between these latitude. In contrast, SLmax $10 \%$ was similar at Lizard and the Capricorn Bunker group where the latter was up to $4 \mathrm{C}^{\mathrm{o}}$ cooler (Figure S2).

Table 2. Parameters from von Bertalanffy growth models and instantaneous mortality on the fishes collected from different distances across the shelf and latitude strata. The maximum age and size (SL) is provided as well as mean age and size for the top $10 \%$ of fish.

\begin{tabular}{|c|c|c|c|c|c|c|c|c|c|c|c|}
\hline Latitude & Shelf & $\begin{array}{l}\text { LAT } \\
\left({ }^{\circ} S\right)\end{array}$ & $n$ & $L_{\infty}$ & $K$ & $\mathbf{T}_{0}$ & $\begin{array}{c}\text { Mortality } \\
\mathrm{m}\left(r^{2}\right)\end{array}$ & $\begin{array}{l}\text { Max } \\
\text { age }\end{array}$ & $\begin{array}{c}\text { Mean } \\
\text { age } 10 \%\end{array}$ & $\begin{array}{c}M a x \\
S L\end{array}$ & $\begin{array}{c}\text { Mean } \\
\text { SL } 10 \%\end{array}$ \\
\hline \multirow[t]{3}{*}{ Lizard Island } & Inner & $14^{\circ}$ & 273 & 88.64 & 1.38 & -0.04 & $0.681(0.61)$ & 7 & 5.9 & 98 & 94 \\
\hline & Mid & $14^{\circ}$ & 237 & 94.53 & 1.52 & -0.04 & $0.578(0.52)$ & 8 & 6.0 & 105 & 102 \\
\hline & Outer & $14^{\circ}$ & 281 & 93.13 & 1.55 & -0.04 & $0.536(0.54)$ & 9 & 5.8 & 105 & 100 \\
\hline \multirow[t]{3}{*}{ Townsville } & Inner & $18^{\circ}$ & 145 & 82.01 & 1.06 & -0.06 & $0.506(0.55)$ & 10 & 8.0 & 100 & 92 \\
\hline & Mid & $18^{\circ}$ & 269 & 97.85 & 1.06 & -0.05 & $0.398(0.47)$ & 10 & 8.5 & 120 & 112 \\
\hline & Outer & $18^{\circ}$ & 293 & 101.16 & 1.16 & -0.04 & $0.432(0.65)$ & 11 & 8.3 & 116 & 110 \\
\hline \multirow[t]{3}{*}{ Whitsundays } & Inner & $19^{\circ}$ & 221 & 83.17 & 1.77 & -0.04 & $0.438(0.35)$ & 11 & 7.6 & 98 & 92 \\
\hline & Mid & $19^{\circ}$ & 140 & 94.96 & 1.14 & -0.05 & $0.245(0.55)$ & 8 & 7.4 & 111 & 104 \\
\hline & Outer & $19^{\circ}$ & 151 & 90.40 & 1.64 & -0.03 & $0.398(0.41)$ & 9 & 6.6 & 104 & 99 \\
\hline Swains & Outer & $22^{\circ}$ & 210 & 94.05 & 1.45 & -0.04 & $0.617(0.64)$ & 8 & 5.7 & 112 & 100 \\
\hline Cap/ Bunker & Outer & $23^{\circ}$ & 239 & 80.84 & 1.58 & -0.04 & $0.414(0.49)$ & 6 & 5.5 & 102 & 93 \\
\hline
\end{tabular}


Table 3. Partially hierarchical ANOVA, testing for differences among Distances across the shelf and three latitudes $n=4$ fish; dependent variable Standard Length top $10 \%$ and Age top 10\%; $\mathrm{p}<0.05 ;{ }^{* * *} \mathrm{p}<0.001$. Distance and latitude were tested as fixed and site as random. $\mathrm{C}=$ Cochran's Test for heterogeneity of the data, $\mathrm{k}=18, \mathrm{df}=3$.

\begin{tabular}{|c|c|c|c|c|c|}
\hline & & $\begin{array}{l}\text { SL } 10 \% \\
\text { C }=0.21, \mathrm{~ns}\end{array}$ & & $\begin{array}{l}\text { Age } 10 \% \\
\text { C }=0.14, n s\end{array}$ & \\
\hline Source of variation & $\mathrm{df}$ & MS & $\mathrm{F}$ & MS & $\mathrm{F}$ \\
\hline Latitude & 2 & 15.7 & 0.35 & 18.0 & $19.6^{* * *}$ \\
\hline Distance & 2 & 874.4 & $19.3^{* * *}$ & 1.43 & 1.55 \\
\hline$L^{*} \mathrm{D}$ & 4 & 264.5 & $5.8^{*}$ & 5.0 & $5.4^{*}$ \\
\hline $\operatorname{Site}\left(L^{*} \mathrm{D}\right)$ & 9 & 45.2 & $10.3^{* * *}$ & 0.92 & 1.15 \\
\hline Residual & 60 & 4.4 & & 0.79 & \\
\hline
\end{tabular}

There was no evidence for variation in the agemax or age $10 \%$ for $A$. polyacanthus at reefs across the shelf and this was consistent at all three latitudes (Figure 3, Table 2). Among latitudes, the agemax of A. polyacanthus at outer reefs was greatest at Lizard, Townsville and the Whitsundays (range 9-11 years), while no fish was older that six years at the Capricorn Bunker Group. Twenty one percent of variation in the age of fish was explained by differences between latitudes, but as for SL, this factor was not significant. There were significant differences between reefs within latitudes, but greatest variation was found at the residual level (63\%). There was a significant negative linear relationship between agemax and latitude (Tropical Gradient) that explained 34\% of the variation; ANOVA for slopes was significantly different from zero (Figure 4). Rather than a counter gradient the relationship was strongly influenced by highest values of agemax on Townsville and Whitsundays reefs.

In some cases replicate reefs within distance strata had different levels of protection, but this did not influence the broad patterns we described for age or size (Table 5). For example, the two inner reefs (Pandora, Havannah; one green one blue) had similar SL max to each other, but both reefs had much smaller fish than two outer reef with different zones where the fish were much larger (Barnett Patches and Myrmidon). Inner reefs at Lizard had very similar agemax regardless of zone as did the two outer reefs compared in the Capricorn Bunker group. Changes in rank were detected for largest and oldest fish with zone indicating that there was no consistent pattern that could be explained by level of protection. There were also no consistent differences in von-Bertalanffy parameters between zones in any of the pairs of fished and unfished zones (Table SP3). In all cases the green zones had been in place for close to the age-max of A. polyacanthus or twice that. 
Figure 3. Age-frequency distributions for A. polyacanthus collected from the 13 sites reefs pooled within distances at each latitude (LOW RESOLUTION IMAGE).

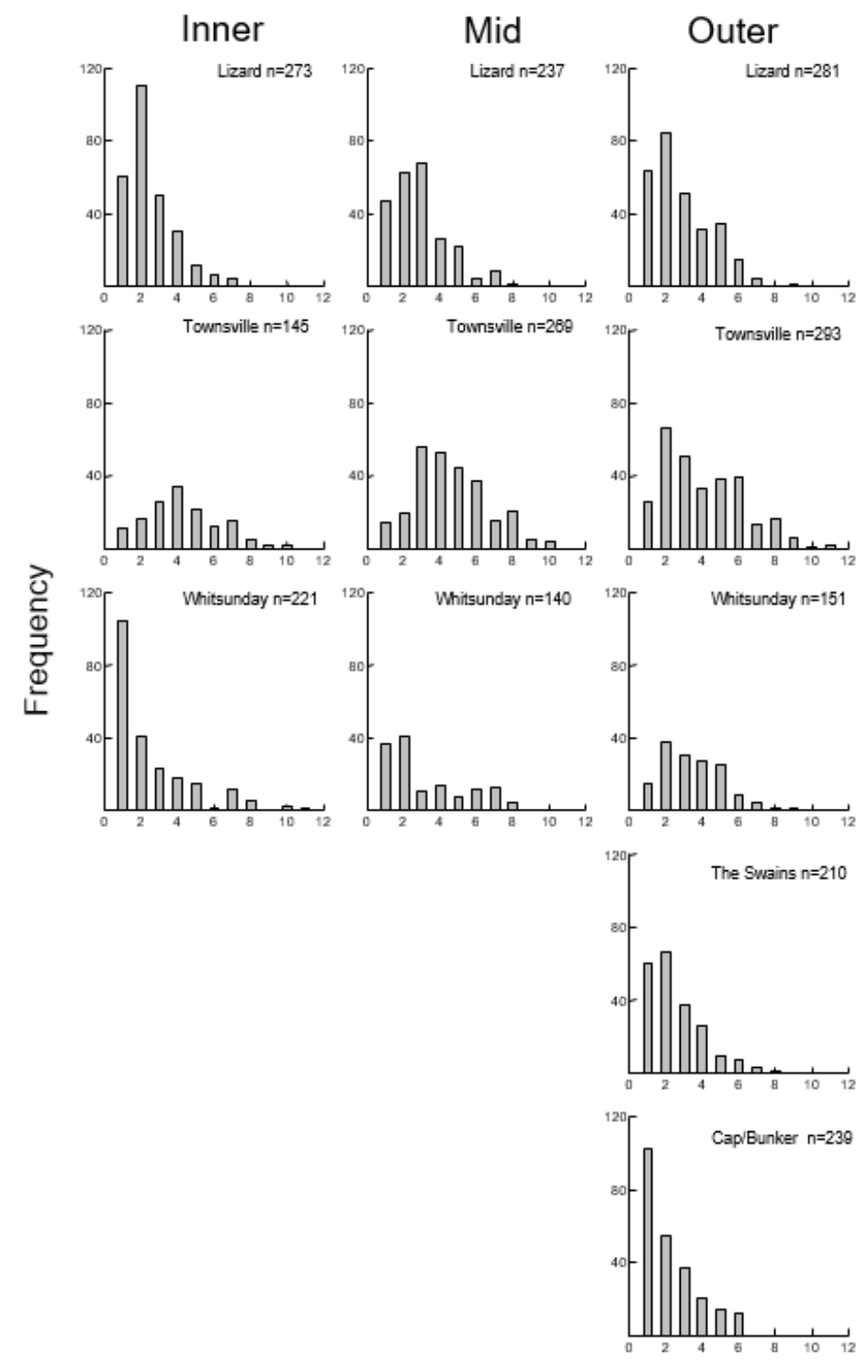

Age (Years) 
Table 4. Nested ANOVA, testing for differences among five latitudes with two reefs nested per latitudes and $n=7$; dependent variable Standard Length top $10 \%$ and Age top $10 \%$; $\mathrm{p}<0.05$; ${ }^{* *}$ $\mathrm{p}<0.001$. Variance components describe the variation contributed to each factor as a percentage. The denominator MS for Latitude is Reef (Lat) and that of Reef (Lat) is the residual.

\begin{tabular}{|c|c|c|c|c|c|}
\hline & & SL $10^{\circ}$ & & & \\
\hline $\begin{array}{l}\text { Source of } \\
\text { variation }\end{array}$ & Df & MS & $\begin{array}{l}\text { Variance } \\
\text { Comp.\% }\end{array}$ & MS & $\begin{array}{l}\text { Variance } \\
\text { Comp.\% }\end{array}$ \\
\hline Latitude & 4 & $486.7 \mathrm{~ns}$ & 29 & $12.95 \mathrm{~ns}$ & 21 \\
\hline Reef (Lat) & 5 & $247.3^{* * *}$ & 58 & $4.67^{*}$ & 15 \\
\hline Residual & 60 & 7.9 & 13 & 1.76 & 64 \\
\hline
\end{tabular}

Figure 4. The relationship between age-max and latitude for A. polyacanthus from outer reefs only. Collections from all reefs are included in this analysis with a minimum of 66 fish (range 66-155) collected at anyone reef, $\mathrm{n}=13$ reefs. $\mathrm{R}^{2}=0.34$, ANOVA for slopes, $\mathrm{F}_{1,1}=5.74, \mathrm{P}<0.03$.

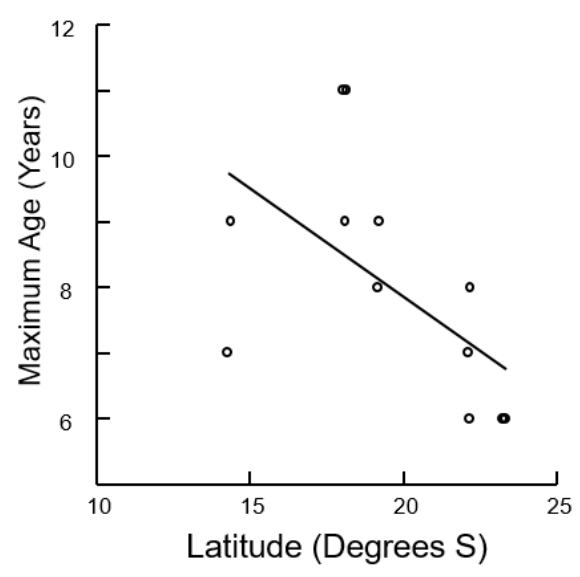

Acanthochromis polyacanthus grew quickly to L $\infty$ at two to three years old (Figure 5). The L $\infty$ of fishes at different distances across the shelf concurred with our comparisons of length frequency in that L $\infty$ was consistently smallest at inner reefs regardless of latitude. The confidence ellipses shown in the Kimura plots also showed consistently small Lo for fish from inner reefs (Figure 6). Although multiple differences among different distances and latitude were detected according to chi-square tests the effect size was always greatest for inner versus mid and outer reefs (Figure $6 \mathrm{~A}$, Table S1). The rate at which fish grew to $\mathrm{L} \infty(\mathrm{K}$, Table 2; Figure 5) was highly variable and not consistent patterns were detected either across the shelf or when comparison were made among the five latitudes with outer reefs. Differences were also detected among reefs with Chi-square tests (Table S1). There was no significant correlation between $\mathrm{K}$ and latitude for 13 reefs over the full latitudinal range of the study (10 degrees). 
Length at age varied with position across the shelf and it was clear that although fish from all reefs grew quickly to $L_{\infty}$ by about 3 years old, growth rate to that $L^{\infty}$ varied with position on the shelf (Figure 5, Table SP4). For example, cross-shelf at the Townsville latitude at age two were about $71 \mathrm{~mm}$ SL compared to 86 and $93 \mathrm{~mm}$ SL at mid and outer shelf reefs. By age three, fish were on average $79 \mathrm{~mm}$ SL at inner reefs and 97 and 100 SL respectively at mid and outer shelf reefs. Significant differences in size at age were detected with distance from shore and this was true for fish aged two and three (Table SP5). There was a consistent pattern of smallest sizes at ages 2 and 3 years nearshore at all latitudes but, the magnitude of size differences between inner reefs and those at mid and outer shelf positions varied with latitude and this resulted in significant interaction between the factors shelf and latitude (Table SP4).

Table 5. The influence of marine protection form fishing on demographic characteristic of Acanthochromis polyacanthus. Summary statistics for both SL and age date are presented as mean (SE) range. Three way partially hierarchical ANOVA are presented with the factors Shelf, Zone, $S^{*} Z$. location (Shelf) and location (Shelf) ${ }^{*}$ in Table SP2; significant factors are listed here. Factor Zone: treatments MPA and Fished. Details of von Bertalanffy parameters by reef and zone are provided in Table SP3.

(a) The top $10 \%$ by size; the interaction location (Shelf) ${ }^{*} \mathrm{~S}$ was significant.

\begin{tabular}{llll}
\hline Shelf & Latitude & MPA & Fished \\
\hline Inner & Lizard & $95.3(0.7) 3$ & $97.5(1.3) 6$ \\
Inner & Townsville & $87.5(0.9) 4$ & $91.5(0.6) 3$ \\
Outer & Townsville & $111.3(1.3) 5$ & $113(1.1) 5$ \\
Outer & Capricorn Bunker & $82(0.9) 4$ & $99(1.5) 6$ \\
\hline
\end{tabular}

(b) The top $10 \%$ of fish by age; the interaction $S^{*} Z$ was significant.

\begin{tabular}{llll}
\hline Shelf & Latitude & MPA & Fished \\
\hline Inner & Lizard & $6(0) 0$ & $6.8(1) 2$ \\
Inner & Townsville & $6.8(0.3) 1$ & $7.8(1) 2$ \\
Outer & Townsville & $9.5(0.6) 3$ & $9(0.7) 3$ \\
Outer & Capricorn Bunker & $6(0) 0$ & $6(0) 0$ \\
\hline
\end{tabular}


Figure 5. Von Bertalanffy growth curves for A. polyacanthus collected with distance across the shelf and with latitude (reefs pooled within distances at each latitude). LOW RESOLUTION IMAGE

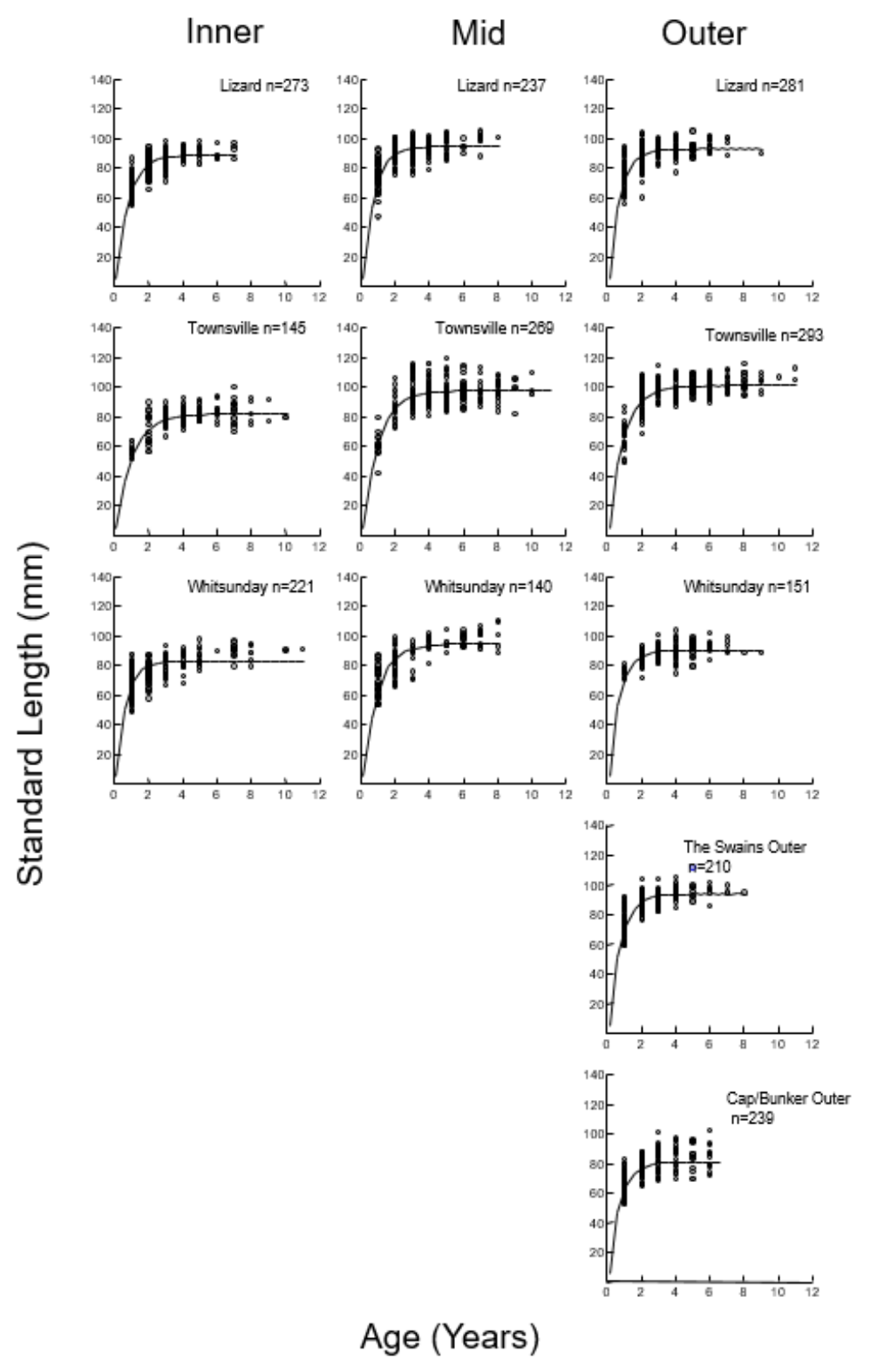


Figure 6. Kumara plots showing a 95\% confidence ellipses for the parameters $K$ (growth coefficient) and $L_{\infty}$ (mean asymptotic length) for A Latitudes with inner mid and outer collection sites and B latitudes where collections where only made at outer reefs (LOW RESOLUTION IMAGE).
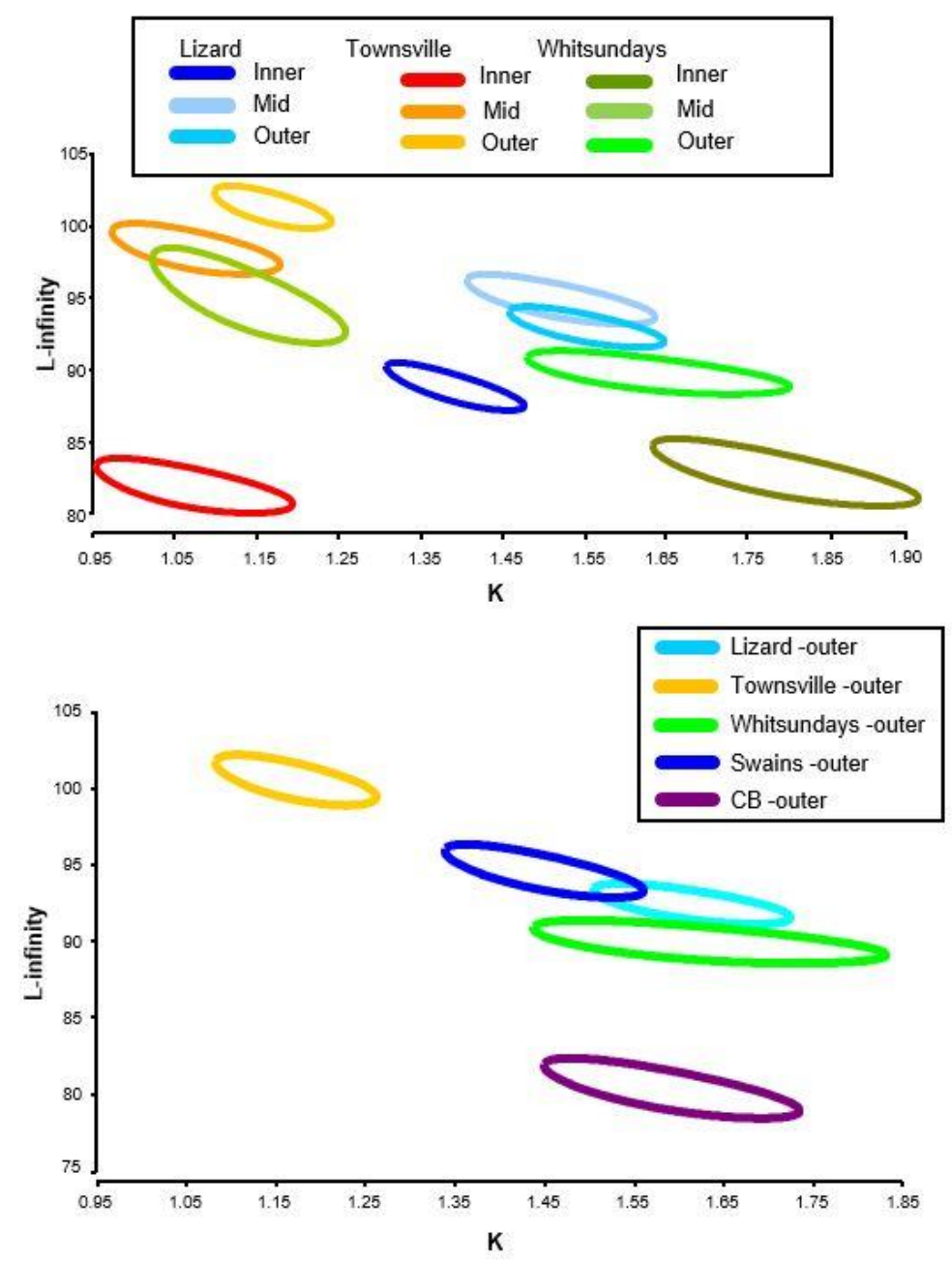

\subsection{Mortality}

Instantaneous mortality rates ranged from 0.69 at Lizard, Inner to 0.245 at Whitsundays mid (Table 2, Figure 7). Mortality rates were consistently higher at inner shelf reefs (Figure 7). This pattern was also apparent from age frequency where the representation of fish greater than 4 years old was relatively low when compared to mid and outer reefs at the same latitude (Figure 3). Although there was a strong trend for mortality rates to drop with latitude, among outer reefs (13 reefs); this relationship, however, was not significant (ANOVA for slopes ns). The relationship was largely derailed by high mortality rates that were detected at the Swains. When all instantaneous mortality relationships were considered, they explained 41 to $65 \%$ of the variation in these relationships. The dependency of the relationships on young and small fish under 3 year old varied with sites within reefs, but there was no consistency with latitude or distance that could have confounded the conclusions relating to spatial differences. 
Figure 7. Age-based instantaneous mortality rates for A. polyacanthus collected with distance across the shelf and with latitude (reefs pooled within distances and latitude). The lower left panel presented instantaneous mortality by distance for each of the three latitudes sampled in this orthogonal combination. LOW RESOLUTION IMAGE

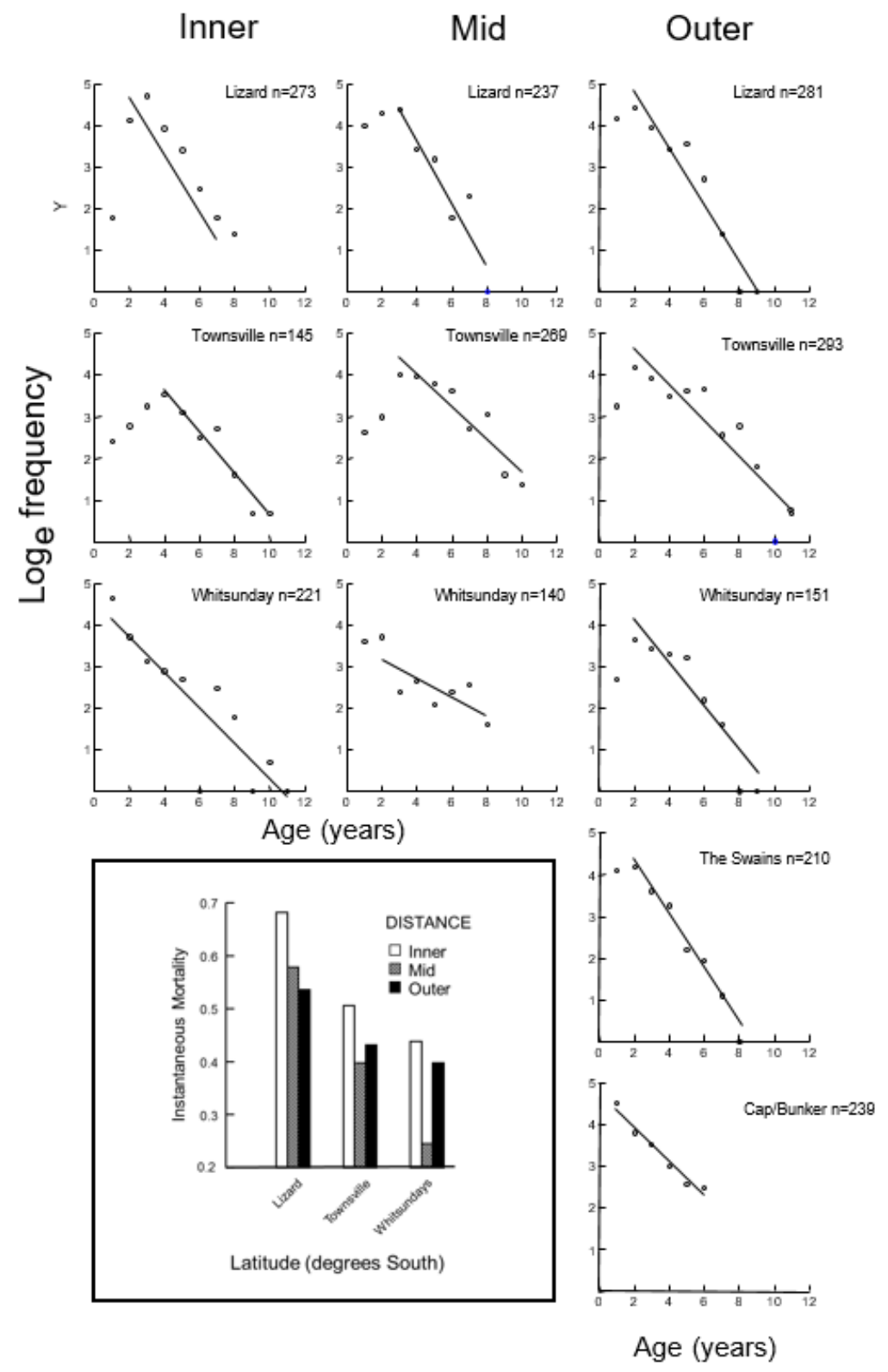




\section{Discussion}

The robustness of this study is in the spatial resolution by distance from shore and latitude that is hard to achieve. In short, we could sample large numbers of fish and that has allowed us to test hypotheses relating to distance across the shelf and with latitude. The data are unequivocal in that position on the continental shelf of the GBR had a substantial influence on the growth and size of A. polyacanthus. The findings of this study concur with our earlier study that focused on one latitude, that of Townsville [23]. There is only one other study we are aware of that addresses this source of variation. Gust et al. demonstrated differences in the demographic characteristics of scarids between mid and outer shelf reefs of the GBR [19]. In this study significant differences in $\mathrm{L}^{\infty}$, growth and mortality were found. Of course, fish have to be found over the full extent of the GBR, or similar geomorphological features, for distance across the shelf to be an issue. For many species they may only be found at one or two distance strata (e.g. [12]) and the danger of confounding latitudinal trends with cross shelf differences would be minimized.

We sampled 13 reef positions over a distance of $1200 \mathrm{~km}$ and $\sim 9$ degrees of latitude and based on this we could test hypotheses concerning variation in demographic characteristics with latitude. Even with this unusually high spatial resolution, few latitudinal gradients were detected. Gradients have been detected for other species over a similar spatial range for size, growth and age-max (e.g. [9, 31]). For example, Cappo et al. [9] found that the body size of L. johnii increased with latitude (=counter gradient) on the GBR and therefore distance from the equator, which concurred with James rule. In contrast, we often only found differences between latitudes on a spatial scales of a few hundreds of kilometers, but not between reefs separated by over 1000 kilometers. For example, one of the greatest differences in size max was found from between the two northern most latitudes, Lizard Townsville. These locations are bathed in similarly warm waters, so perhaps at this spatial local factors such as the supply of planktonic food may play a major role on patterns of growth as at least one of our offshore sites Myrmidon reef is well known for upwelling [32, 33].

We found variation between reefs within a latitude, both for the largest and oldest fish. Fry and Milton [34] also found variation in demographic metrics within a location that 'made it difficult to detect differences with latitude'. They did, however, find variation in L. malabaricus in size and age over a broad longitudinal range (Western to eastern Australia). In contrast, to the small scale variation we found, Williams et al [35] did not detect differences the growth and age-max of Lethrinus miniatus; among reefs within locations. However, there were different among regions separated by hundreds of kms or up to 4 degrees; these patterns were consistent when they were compared five years later [36]. Variation in demographics among reefs within a latitude may be due to factors such as the density of conspecifics, availability of prey and predatory regimes. Ong et al [37] examined differences between Lutjanus bohar populations at the same latitude from the and west coast of Australia. They argued that the differences they found local factors such as oceanography and ecological differences were the primary drivers of differences in demographics. Our findings across the continental shelf of the GBR and big differences in SLmax at some sites such as Myrmidon (Townsville) align with this view.

Although most of the latitudinal trends we tested for SL, growth and age were not significant (=Tropical gradient), we did find a variable, but significant, negative relationship between the agemax of A. polyacanthus and latitude. Piddocke et al., (2015) also found a negative relationship between agemax and temperature and growth for Lutjanus argentimaculatus. There was no relationship A. polyacanthus between growth to $\mathrm{L} \infty(\mathrm{K})$ with latitude. Although seasonal cycles in temperature between 14 and $24^{\circ} \mathrm{S}$ were about four degrees (Fig. SP2), greatest latitudinal differences were found between Lizard and Townsville latitudes where seasonal temperature cycles were similar. Latitude is clearly a rough proxy for a temperature gradient given the complexities of oceanography [8]. We also found that SLmax was similar at the latitudinal extremes in our study where seasonal difference in temperature were greatest; this does not align with the Temperature Size Rule [6]. Of course, differencs in growth may manifest itself at the more extreme ends of the temperature and food availablilty spectrum. For example, experiments on A. polyacanthus have 
demonstrated that the growth potential of fish can be inhibited regardless of how much food is available at high temperatures (e.g., $31^{\circ} \mathrm{C},[38]$ ).

The consistency of relatively small size of fish at inner reefs of the GBR suggests some similarity of the biophysical drivers influencing growth and size maxima. Shallow waters of the GBR can get very warm in summer and this area is notorious for coral bleaching when reefs further from shore are below the bleaching threshold of $31^{\circ} \mathrm{C}$ [39]. It is highly likely the growth potential of A. polyacanthus can be inhibited at these times, as has been shown experimentally [38]. Sediment loads are generally higher on inshore reefs [40] and this could reduce the intake of food of a planktivore [41]). We also have some evidence from unpublished cross shelf plankton samples that the abundance of small plankton (i.e., copepodites etc retained by 100 micron mesh) is about a quarter that of mid and outer reefs. A combination of these factors, therefore are most likely drivers for the patterns we found. Further, the patterns are unequivocal because we had an orthogonal; design with distance across the shelf and three latitudes that showed similar patterns.

Our findings concur with other studies that variation in environmental conditions within a latitude can have a strong influence on demographic characteristics and in some cases this variation can be a great as some purported 'gradient models'. For example, Ong et al [37] studied spatial patterns in the growth variability of Lutjanus bohar over a similar latitudinal range in tropical waters, they concluded that the major drivers were variation in local climatic patterns (e.g., oceanography) and biological factors. Similarly, Gust et al [19] found differences in size and age-maxima of scarids between mid and outer reefs of the GBR over a narrow latitudinal range. Gillanders [42] also found great differences in patterns of growth of a large subtropical labrid over spatial scales of kilometres. These studies further emphasize the importance of local factors in determining demographic characteristics.

Mortality may also have a role in the cross shelf patterns that we found (e.g. [19]). Mortality rates were consistency highest at inner reefs and the numbers of fish over 4 years old were less inshore when compared to mid and outer reefs. Interestingly the age-max of inner reefs was similar to mid and outer, it is just that few fish reached ages over. Accordingly, mortality alone does not explain the patterns in age-maxima that we found with distance across the GBR. There can be temporal variation in mortality rates [36]) and, this is highly likely where the size of pulses in recruitment alter values of $Z$. The methods for calculating instantaneous mortality assume even recruitment among years. However, this is unlikely to alter the consistency of the pattern of highest mortalities nearshore though more information on temporal patterns of recruitment with distance from shore would help to resolve this issue.

Although there was a strong trend for mortality rates to drop with latitude this was not significant. The relationship was largely derailed by high mortality rates that were detected at the Swains. Similarly, no clear latitudinal trend in mortality was also found by Williams et al [35] for Lethrinus miniatus.

Although A. polyacanthus is still considered a single species [24], the variation in colouration that is well known suggests that insipient speciation is likely. A contributing factor to variation in demographic parameters, therefore, could be due in part to phenotypic plasticity relating to genetic differences [1,43]. However, the cross shelf patterns found were robust regardless of latitude and colour morph. Fish were smallest inshore at Lizard where all fish were the brown and white colour morph (Figure S1a); the Townsville latitude was again brown and whites with some additional golden colouration on the chin at inner reefs (Figure S1b). Two different morphs were collected on the Whitsundays transect (Figure S1c) while the dark colour morph were only found from the southern two latitudes of the GBR (Figure S1d). Although the Age-max for Capricorn Bunker fish was six years, oldest fish of the same colour morph from the Swains were up to eleven years old; this equated with the highest value found at any latitude and distance.

A concern for many ageing studies that deal with commercial species such as lutjanids and lethrinids is that natural patterns, be they by distance across the shelf or latitude can be confounded by differences in fishng pressure that could affect differences in SLmax, $\mathrm{L}^{\infty}$, agemax, and of course mortality (ie a combination of fishing mortality F and natural mortality M [3]). In contrast, the small damselfishes in this study are not subject to a fishery and they don't attract much attention from the 
aquarium trade. Furthermore, although top-down effects from large predators have the potential to alter density of small prey and affect mortality rates. Inverse relationships between the numbers of predators and numbers of prey have been detected when comparisons have been made between marine sanctuary zones and fishes areas at the same latitude [4]. Further, Gust et al [19] concluded that differences in age-maxima cross shelf were drivern by predation. However we found no evidence for such patterns in our study.

\section{Conclusions}

In conclusion, we found that demographic characteristics of $A$. polyacanthus varied greatly across the continental shelf of the Great Barrier Reef; this pattern was consistent within three latitudes. SLmax was smallest and growth slowest at inner reefs and, mortality rates were also greatest at this distance. A comparison among outer reefs over $10^{\circ}$ of latitude detected a 'Tropical Gradient of decreased agemax with an increase in latitude. No other latitudinal trends in L, K and age were detected, but there was significant variation between outer reefs at the same latitude. We suggest that local environmental factors had the greatest effect on patterns of size and growth and this should be has been considered in latitude-based gradient models of fish demographic characterietics.

Supplementary Materials: The following are available online at www.mdpi.com/xxx/s1, Figure SP1 Colour morphs of A.polyacanthus, Figure SP2 Temperature data at each outer reefs at three latitudes. Table SP1 results of chi-square tests from Kimura plots. Table SP 2. Partially hierarchical ANOVA, testing for differences among Distances across the shelf and Zone (MPA and fished). Table SP3 Reef status comparison of age and growth parameters, Table SP4, Mean size of A. polyacanthus at ages 2 and 3 Table SP 5 Three factor ANOVA, Factors: distance and latitude with the response variable SL for fish aged 2 and 3.

Author Contributions: MJK, designed the study, collected the fish with coauthors, contributed to the analyses and drafted the manuscript. MO'C collected the fish with other coauthors, aged fish from otoliths and contributed to the presentation for data and edited the manuscript. DW collected the fish with other coauthors, contributed to the analyses

Funding: The project was partly funded by an ARC Grant to MJK.

Acknowledgments: We would like to thank H. Patterson, C. Bunt, W. Robbins and the crew of the R.V. Orpheus and M.V. Melantre for field assistance during this study. We also thank J. Ackerman for analytical advice and expertise and J.H. Choat for constructive comments on the manuscript. Thanks to Jacqui Stuart for the exquisite images of fish. This is a contribution from Orpheus Island Research Station, One Tree Island Field Station and the Reef and Ocean Ecology Laboratory at James Cook University.

Conflicts of Interest: The authors declare no conflicts of interest. 


\section{References}

1. Conover, D.O., Brown, J.J., and Ehtisham, A. (1997). Countergradient variation in growth of young striped bass (Morone saxatilis) from different latitudes. Can. J. Fish. Aquat. Sci 54, 2401-2409.

2. Boehlert, G.W., and Kappenman, R.F. (1980). Variation of growth with latitude of two species of rock fishes (Sebastes pinniger and $S$. diploproa) from the North Eastern Pacific Ocean Mar. Ecol. Prog. Ser. 3, 1-10.

3. Hilborn, R., and Walters, C.J. (1992). Quantitative fisheries stock assessment, (London: Chapman \& Hall).

4. Boaden, A.E., and Kingsford, M.J. (2015). Predators drive community structure in coral reef fish assemblages Ecosphere 6, 1-33.

5. Houde, E.D. (1989). Comparative growth, mortality, and energetics of marine fish larvae - temperature and implied latitudinal effects. Fish. Bull. 87, 471-495.

6. Atkinson, D. (1994). Temperature and organism size: a biological law for ectotherms. In Advances in Ecological Research, Vol 25, Volume 25, M. Begon and A.H. Fitter, eds. (London: Academic Press Ltd-Elsevier Science Ltd), pp. 1-58.

7. Yamahira, K., and Conover, D.O. (2002). Intra- vs. interspecific latitudinal variation in growth: Adaptation to temperature or seasonality? Ecology 83, 1252-1262.

8. Choat, J.H., and Robertson, D.R. (2002). Age-based studies on coral reef fishes. Coral Reef Fishes: Dynamics and Diversity in a Complex Ecosystem, (San Diego: Academic Press).

9. Cappo, M., Marriott, R.J., and Newman, S.J. (2013). James's rule and causes and consequences of a latitudinal cline in the demography of John's Snapper (Lutjanus johnii) in coastal waters of Australia. Fish. Bull. 111, 309-324.

10. Piddocke, T.P., Butler, G.L., Butcher, P.A., Stewart, J., Bucher, D.J., and Christidis, L. (2015). Age and growth of mangrove red snapper Lutjanus argentimaculatus at its cool-water-range limits. J. Fish Biol. 86, 1587-1600.

11. Williams, A.J., Davies, C.R., Mapstone, B.D., Currey, L.M., Welch, D.J., Begg, G.A., Ballagh, A.C., Choat, J.H., Murchie, C.D., and Simpfendorfer, C.A. (2009). Age-based demography of humpback grouper Cromileptes altivelis: implications for fisheries management and conservation. Endangered Species Research 9, 67-79.

12. Williams, D.M. (1982). Patterns of distribution of fish communities across the central Great Barrier Reef lagoon. Coral Reefs 1, 35-43.

13. Williams, D.M., Russ, G., and Doherty, P.J. (1986). Reef Fish: large scale distribution and recruitment. Oceanus 29, 76-82.

14. Russ, G. (1984). Distribution and abundance of herbivorous grazing fishes in the central Great Barrier Reef. I. Levels of variability across the entire continental shelf. Mar. Ecol.-Prog. Ser. 20, 23-34.

15. Williams, D.M., and Hatcher, A.I. (1983). Structure of fish communities on outer slopes of inshore, midshelf and outer shelf reefs of the Great Barrier Reef. Mar. Ecol.-Prog. Ser. 10, 239-250. 
16. Furnas, M.J. (2003). Catchments and Corals: terrestrial runoff to the Great Barrier Reef, (Townsville: Australian Institute of Marine Science).

17. Bainbridge, Z.T., Wolanski, E., Alvarez-Romero, J.G., Lewis, S.E., and Brodie, J.E. (2012). Fine sediment and nutrient dynamics related to particle size and floc formation in a Burdekin River flood plume, Australia. Mar. Pollut. Bull. 65, 236-248.

18. Wolanski, E. (2001). Oceanographic processes of coral reefs: Physical and Biological Links in the Great Barrier Reef, (Boca Raton: CRC Press).

19. Gust, N., Choat, J.H., and Ackerman, J.L. (2002). Demographic plasticity in tropical reef fishes. Marine Biology 140, 1039-1051.

20. Russ, G.R., and Alcala, A.C. (1989). Effects of intense fishing pressure on an assemblage of coral reef fish. Mar. Ecol.-Prog. Ser. 56, 13-27.

21. Babcock, R.C., Shears, N.T., Alcala, A.C., Barrett, N.S., Edgar, G.J., Lafferty, K.D., McClanahan, T.R., and Russ, G.R. (2010). Decadal trends in marine reserves reveal differential rates of change in direct and indirect effects. Proceedings of the National Academy of Sciences of the United States of America 107, 18256-18261.

22. Williamson, D.H., Russ, G.R., and Ayling, A.M. (2004). No-take marine reserves increase abundance and biomass of reef fish on inshore fringing reefs of the Great Barrier Reef. Environ. Conserv. 31, 149-159.

23. Kingsford, M.J., and Hughes, J.M. (2005). Patterns of growth, mortality and size of a tropical damselfish Acanthochromis polyacanthus across the continental shelf of the Great Barrier Reef. Fish. Bull. 103, 561-573.

24. Allen, G.R. (1991). Damselfishes of the world, (Melle, Germany: Mergus).

25. Allen, G.R. (1975). Damselfishes of the south seas, (Neptune Cuty NJ: TFH Publications).

26. Doherty, P.J., Mather, P., and Planes, S. (1994). Acanthochromis polyacanthus, a fish lacking larval dispersal, has genetically differentiated populations at local and regional scales on the Great Barrier Reef. Marine Biology 121, 11-22.

27. Underwood, A.J. (1997). Experiments in Ecology: their logical design and interpretation using analysis of variance, (Cambridge: Cambridge University Press).

28. Schnute, J. (1981). A versatile growth model with statistically stable parameters. Canadian Journal of Fisheries and Aquatic Science 38, 1128-1140.

29. Pauly, D. (1984). Population dymanics in tropical waters. ICLARM Stud. Rev. 8, $1-325$.

30. Ricker, W.E. (1975). Computation and interpretation of biological statistics of fish populations. Department of the Environment, .

31. Kritzer, J.P. (2002). Variation in the population biology of stripey bass Lutjanus carponotatus within and between two island groups on the Great Barrier Reef. Mar. Ecol. Prog. Ser. 243, 191-207.

32. Walther, B.D., Kingsford, M.J., and McCulloch, M.T. (2013). Environmental Records from Great Barrier Reef Corals: Inshore versus Offshore Drivers. Plos One 8, 11 .

33. Kingsford, M.J., Hughes, J.M., and Patterson, H.M. (2009). Otolith chemistry of the non-dispersing reef fish Acanthochromis polyacanthus: cross-shelf patterns from the central Great Barrier Reef. Marine Ecology-Progress Series 377, 279-288. 
34. Fry, G.C., and Milton, D.A. (2009). Age, growth and mortality estimates for populations of red snappers Lutjanus erythropterus and L. malabaricus from northern Australia and eastern Indonesia. Fish. Sci. 75, 1219-1229.

35. Williams, A.J., Davies, C.R., Mapstone, B.D., and Russ, G.R. (2003). Scales of spatial variation in demography of a large coral-reef fish - an exception to the typical model? Fish. Bull. 101, 673-683.

36. Williams, A.J., Mapstone, B.D., and Davies, C.R. (2007). Spatial patterns in cohort-specific mortality of red throat emperor, Lethrinus miniatus, on the Great Barrier Reef. Fish Res. 84, 328-337.

37. Ong, J.J.L., Rountrey, A.N., Marriott, R.J., Newman, S.J., Meeuwig, J.J., and Meekan, M.G. (2017). Cross-continent comparisons reveal differing environmental drivers of growth of the coral reef fish, Lutjanus bohar. Coral Reefs 36, 195-206.

38. Munday, P.L., Kingsford, M.J., O'Callaghan, M.D., and Donelson, J.M. (2008). Elevated temperature restricts growth potential of the coral reef fish Acanthochromis polyacanthus. Coral Reefs 27, 927 - 931

39. Hughes, T.P., Kerry, J.T., Baird, A.H., Connolly, S.R., Dietzel, A., Eakin, C.M., Heron, S.F., Hoey, A.S., Hoogenboom, M.O., Liu, G., et al. (2018). Global warming transforms coral reef assemblages. Nature 556, 492-+.

40. Wolanski, E., Richmond, R., McCook, L., and Sweatman, H. (2003). Mud, marine snow and coral reefs - The survival of coral reefs requires integrated watershed-based management activities and marine conservation. Am. Scientist 91, 44-51.

41. Wenger, A.S., Johansen, J.L., and Jones, G.P. (2012). Increasing suspended sediment reduces foraging, growth and condition of a planktivorous damselfish. Journal of Experimental Marine Biology and Ecology 428, 43-48.

42. Gillanders, B.M. (1997). Comparison of growth rates between estuarine and coastal reef populations of Achoerodus viridis (Pisces: Labridae). Mar. Ecol.-Prog. Ser. 146, 283-287.

43. Vigliola, L., and Meekan, M.G. (2002). Size at hatching and planktonic growth determine post-settlement survivorship of a coral reef fish. Oecologia 131, 89-93. 


\section{Supplementary material 1}

Figure S1 Colour morphs of $A$. polyacanthus from different latitudes and distances across the shelf (ie inner, mid and outer). Lines indicate where a colour morph was found at more than once distance across the shelf. Where there are two fish at a latitude the line refers to fish two.

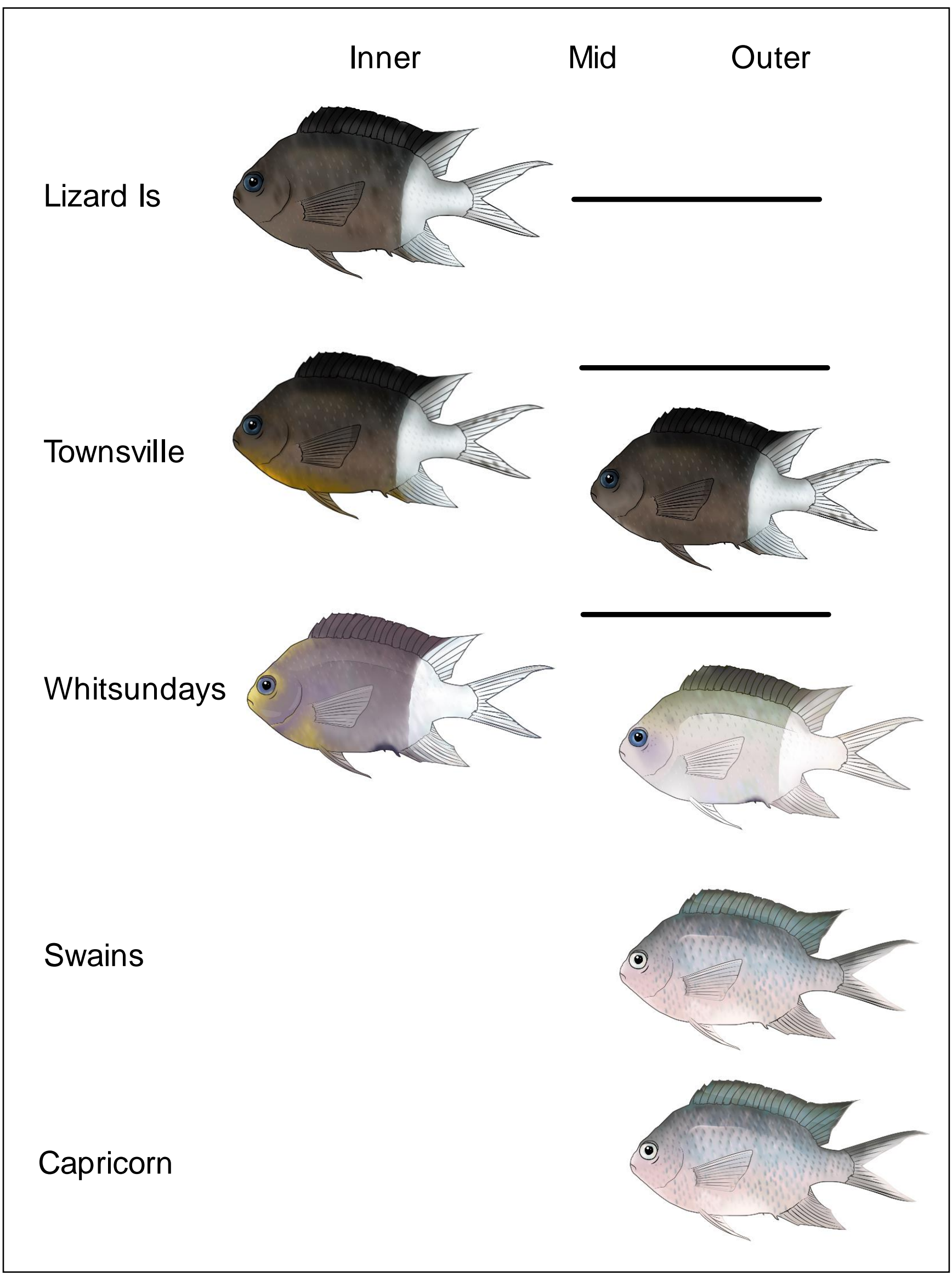


Figure S2 Temperature data collected from loggers in shallow $(10 \mathrm{~m})$ and deep $(30 \mathrm{~m})$ water at offshore three latitudes (Lizard - Yonge Reef; Townsville-Myrmidon Reef, Capricorn Bunker, One Tree Island) that encompassed the latitudinal range of the study. The x-axis is presented in two month increment for the years 2007 - 2009.

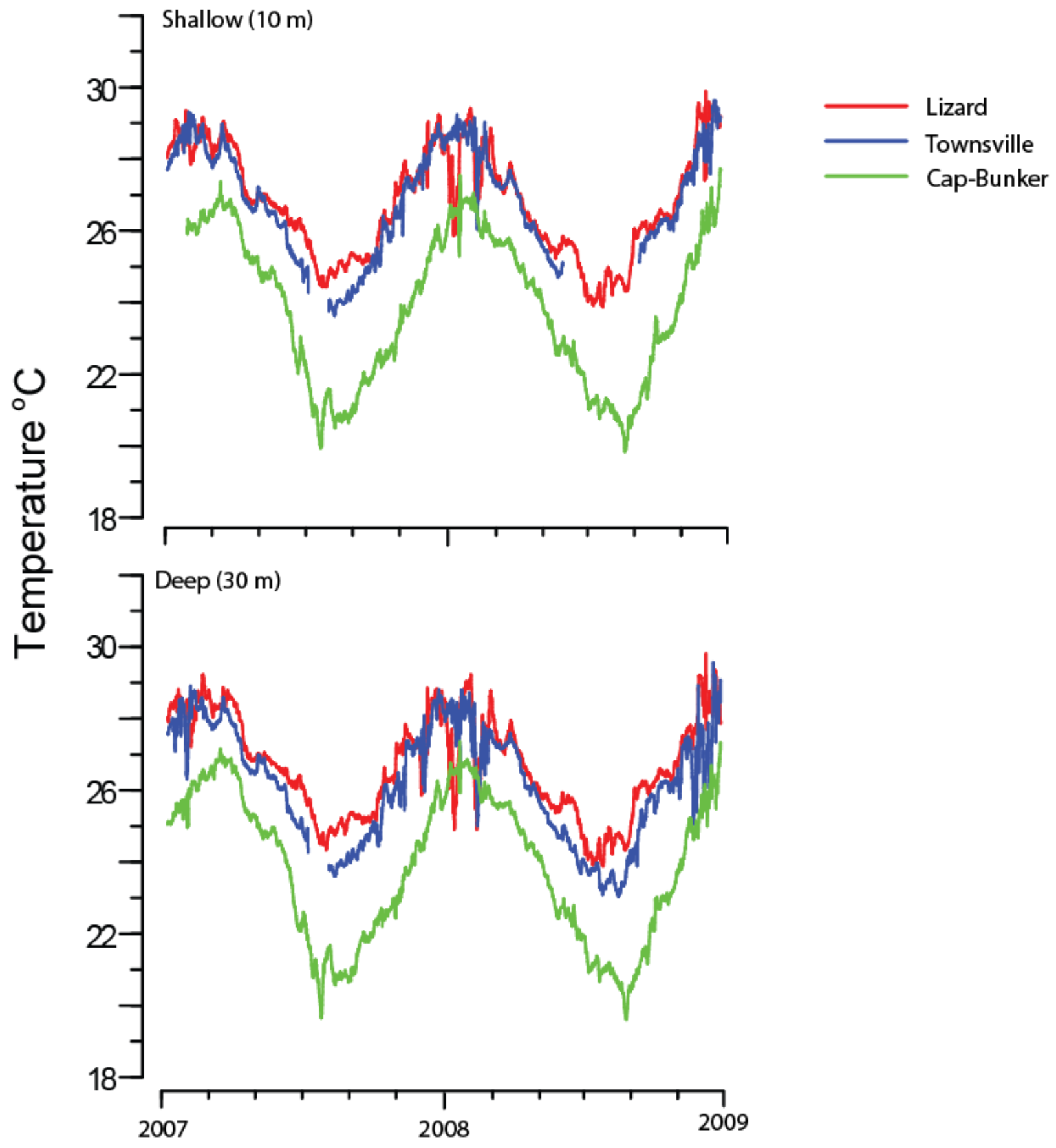


Table SP1 results of chi-square tests from Kimura plots (Figure 6) Likelihood ratio tests showed that patterns in growth differed among regions and distance strata $\left(X^{2}, 24=931.78, p<0.001\right)$. Post hoc tests indicated that this significant result was due to significant differences in growth between almost all combinations of region and shelf position. In general the effect within each region was explained by differences in the value of the estimated $L_{\infty}$ rather than $K$ or $t_{0}$, however this result was variable. The estimate of $L_{\infty}$ was generally lower for inner-shelf distance strata for all regions however this wasn't consistent statistically. Growth patterns for the inner-shelf distance strata were different among all regions. For the outer-shelf distance strata across the regions Lizard Island, Townsville, Whitsundays, Swains and the Capricorn-Bunkers significant differences in growth patterns were detected $\left(X^{2}, 12=464.92, p<0.001\right)$. This difference was due to a higher $L_{\infty}$ for the Townsville region and a lower $L_{\infty}$ for the Capricorn-Bunker region, than all other regions. The outer-shelf strata for the Lizard Island, Whitsundays and Swains regions were generally similar. Estimates of the $K$ parameter among regions were generally similar except for Townsville where it tended to be lower.

\begin{tabular}{lcccccc} 
Test & $\mathbf{X}^{\mathbf{2}}$ coincident & $\mathbf{d f}$ & $\mathbf{p}$ & Linf p & K p & to p \\
\hline Overall & 931.78 & 24 & $<0.001$ & $<0.001$ & $<0.001$ & $<0.001$ \\
LI inner v LI outer & 101.87 & 3 & $<0.001$ & $<0.001$ & 0.932 & 0.501 \\
LI inner v LI mid & 115.33 & 3 & $<0.001$ & $<0.001$ & 0.908 & 0.767 \\
LI mid v LI outer & 3.871 & 3 & 0.276 & 0.347 & 0.862 & 0.795 \\
Tvl inner v Tvl outer & 396.45 & 3 & $<0.001$ & $<0.001$ & 0.002 & 0.002 \\
Tvl inner v Tvl mid & 233.33 & 3 & $<0.001$ & $<0.001$ & 0.012 & 0.004 \\
Tvl mid v Tvl outer & 33.84 & 3 & $<0.001$ & $<0.001$ & 0.858 & 0.712 \\
Whit inner v Whit outer & 81.07 & 3 & $<0.001$ & 0.401 & 0.03 & 0.057 \\
Whit inner v Whit mid & 47.16 & 3 & $<0.001$ & 0.677 & 0.242 & 0.073 \\
Whit mid v Whit outer & 28.97 & 3 & $<0.001$ & 0.013 & 0.135 & 0.634 \\
LI inner v Tvl inner & 136.34 & 3 & $<0.001$ & $<0.001$ & 0.084 & 0.497 \\
LI inner v Whit inner & 64.54 & 3 & $<0.001$ & 0.075 & $<0.001$ & $<0.001$ \\
Tvl inner v Whit inner & 47.32 & 3 & $<0.001$ & $<0.001$ & 0.001 & $<0.001$
\end{tabular}


Table SP 2. Partially hierarchical ANOVA, testing for differences among Distances across the shelf and Zone (MPA and fished) $\mathrm{n}=4$ fish; dependent variable Standard Length top $10 \%$ and Age top 10\%; ${ }^{*} \mathrm{p}<0.05 ;{ }^{* *} \mathrm{p}<0.001$. Distance and latitude were tested as fixed and site as random. $\mathrm{C}=$ Cochran's Test for heterogeneity of the data, $\mathrm{k}=18, \mathrm{df}=3$.

\begin{tabular}{|c|c|c|c|c|c|}
\hline & & \multicolumn{2}{|c|}{$\begin{array}{l}\text { SL } 10 \% \\
C=0.21 \mathrm{~ns}\end{array}$} & \multicolumn{2}{|c|}{$\begin{array}{l}\text { Age } 10 \% \\
C=0.14, \text { ns }\end{array}$} \\
\hline $\begin{array}{l}\text { Source of } \\
\text { variation }\end{array}$ & $\mathrm{df}$ & MS & $\mathrm{F}$ & MS & $\mathrm{F}$ \\
\hline Distance & 1 & 760.5 & 0.7 & 0.03 & 0.03 \\
\hline Zone & 1 & 312.5 & 0.3 & 5.3 & 5.8 \\
\hline$S^{*} Z$ & 1 & 66.1 & 0.06 & 47.5 & $52.5^{*}$ \\
\hline Loc(Shelf) & 2 & 1089 & 6.33 & 0.9 & 1 \\
\hline Loc(Shelf)*zone & 2 & 172.1 & $39.1^{* * *}$ & 0.9 & 1 \\
\hline Residual & 24 & 4.4 & & 0.9 & \\
\hline
\end{tabular}


Table SP3 Reef status comparison of age and growth parameters between Protected zones (Marine National Park Zone B -Green=unfished) with General Use Zones (Blue - fished).

\begin{tabular}{|c|c|c|c|c|c|c|c|c|}
\hline & & $\mathbf{n}$ & $\mathrm{L}_{\infty}$ & $\mathbf{K}$ & To & $\mathbf{r}^{2}$ & $\begin{array}{l}\text { Max } \\
\text { age }\end{array}$ & $\begin{array}{l}\text { Time } \\
\text { Green } \\
\text { (Years) }\end{array}$ \\
\hline Havannah & Inner & 82 & 79.98 & 1.39 & -0.05 & 0.37 & 10 & \\
\hline Pandora & Inner & 43 & 77.43 & 1.39 & -0.05 & 0.66 & 9 & 14 \\
\hline Myrmidon & Outer & 81 & 103.29 & 1.27 & -0.04 & 0.53 & 11 & \\
\hline Barnett Patches & Outer & 113 & 100.073 & 1.17 & -0.04 & 0.71 & 11 & 14 \\
\hline Lamont & Outer & 73 & 92.52 & 1.36 & -0.04 & 0.61 & 6 & \\
\hline One Tree Island & Outer & 81 & 77.13 & 1.46 & -0.05 & 0.60 & 6 & 20 \\
\hline Martin & Inner & 160 & 88.49 & 1.37 & -0.04 & 0.63 & 7 & \\
\hline Eagle & Inner & 92 & 90.18 & 1.25 & -0.05 & 0.63 & 8 & 9 \\
\hline
\end{tabular}


Table SP4 Mean size of $A$. polyacanthus at ages 2 and 3 collected from different distances across the shelf and latitude strata on the GBR, Australia

\begin{tabular}{|c|c|c|c|c|c|c|}
\hline Location & $\begin{array}{c}\text { Shelf } \\
\text { Position } \\
\end{array}$ & $\begin{array}{l}\text { LAT } \\
\left({ }^{\circ} \mathbf{S}\right) \\
\end{array}$ & $n$ & $\begin{array}{l}\text { Mean size } \\
\text { at } 2 \text { (SE) }\end{array}$ & $n$ & $\begin{array}{l}\text { Mean size } \\
\text { at } 3 \text { (SE) }\end{array}$ \\
\hline \multirow[t]{3}{*}{ Lizard Island } & Inner & $14^{\circ}$ & 110 & $83(0.55)$ & 50 & $86(0.78)$ \\
\hline & Mid & $14^{\circ}$ & 63 & $90(0.83$ & 67 & $93(0.74)$ \\
\hline & Outer & $14^{\circ}$ & 82 & $88(0.74)$ & 50 & $92(0.54)$ \\
\hline \multirow[t]{3}{*}{ Townsville } & Inner & $18^{\circ}$ & 16 & $71(2.68)$ & 26 & 79 (1.04) \\
\hline & Mid & $18^{\circ}$ & 20 & $86(2.14)$ & 57 & $97(1.26)$ \\
\hline & Outer & $18^{\circ}$ & 66 & $93(1.11)$ & 51 & $100(0.72)$ \\
\hline \multirow[t]{3}{*}{ Whitsundays } & Inner & $19^{\circ}$ & 41 & 75 (1.08) & 23 & $81(1.39)$ \\
\hline & Mid & $19^{\circ}$ & 40 & 80 (1.16) & 11 & $78(2.79)$ \\
\hline & Outer & $19^{\circ}$ & 38 & $87(0.71)$ & 31 & $90(0.86)$ \\
\hline Swains & Outer & $22^{\circ}$ & 67 & $89(0.60)$ & 37 & $91(0.83)$ \\
\hline Cap/ Bunker & Outer & $23^{\circ}$ & 52 & $78(0.85)$ & 36 & $83(1.30)$ \\
\hline
\end{tabular}


Table SP 5 Three factor ANOVA, Factors, distance (F) and latitude with the response variable SL for fish aged 2 and 3. Heterogeneity of the data were checked with Cochran's C, k=9 and df =19; Age 2 C=0.17 NS; Age 3 $\mathrm{C}=0.23$ *.

\begin{tabular}{|c|c|c|c|c|c|}
\hline & & \multicolumn{2}{|c|}{$\begin{array}{l}\text { SL at age } 2 \\
C=0.17 \mathrm{~ns}\end{array}$} & \multicolumn{2}{|c|}{$\begin{array}{l}\text { SL at age } 3 \\
\mathrm{C}=0.23, *\end{array}$} \\
\hline $\begin{array}{l}\text { Source of } \\
\text { variation }\end{array}$ & $\mathrm{df}$ & MS & $\mathrm{F}$ & MS & $\mathrm{F}$ \\
\hline Distance & 2 & 1497 & $27.3^{* * *}$ & 1393 & $31.1^{* * *}$ \\
\hline Latitude & 2 & 789.6 & $14.4^{* * *}$ & 262.8 & $5.9^{* *}$ \\
\hline$D^{*} \mathrm{~L}$ & 4 & 318.5 & $318.5^{* * *}$ & 192.7 & $4.3^{*}$ \\
\hline Residual & 143 & 4.4 & & 44.8 & \\
\hline
\end{tabular}

